\title{
INTERVIEW
}

\author{
SARENA ABDULLAH
}

Universiti Sains Malaysia

EILEEN LEGASPI-RAMIREZ

University of the Philippines

\section{Art and the community in the Philippines: Conversation between Sarena Abdullah and Eileen Legaspi-Ramirez}

Sarena Abdullah (S): Hi Eileen Legaspi-Ramirez thank you for agreeing to this online interview. We have worked together under the Ambitious Alignments project in 2015, though the project was under a different research, I also know that you have worked with the community realms back in the Philippines. On behalf of the Art \& the Public Sphere journal, I would like to thank you in agreeing in sharing with us the arts engagement especially within the construct of the larger public sphere in the Philippines.

Eileen Legaspi-Ramirez (E): Always happy to share from where I'm able, Sarena. Thanks too for your interest!

S: When we are speaking art and the public, one of the section in mind are the communities, who are the major artistic communities in the Philippines? 
E: We're specifically talking contemporary art, yes? And are we limiting the discussion to artists/organizations that self-identify with working with communities? I ask this because I think we may need to make a distinction between communities in which core groups of artists work. For example, an artist might choose to make their art outside the typical gallery/museum space but may not be wholly interested in the participative aspect of doing work in collaboration and subject to community processes. On the other end of the spectrum would be artists working with communities/those explicitly aligning their practices with community engagement, and where the art might actually take a backseat to the processes of immersion and organizing. Another useful distinction could also be made: artists coming into a community setting with the expressed purpose of making art on site, and those artists more explicitly wishing to situate their practice within communities. So in the latter case, we might say that the art made, if it eventually gets made at all in light of participative processes, is just one of many other aspects of the whole venturing forth into a community. Please let me know if we're on the same page so far.

S: I am thinking here more along the lines of visual artists who are working with the communities. Who are they? Their motivation in working with the communities though I presume that they have a fine arts degree?

E: I would say they come from a broader range of fields than that. While there are indeed school-trained artists among those working with communities, there is also a distinct anti-institutional strain that also co-occupies that space of practice (thus you have anarchists/autonomous networks that are a composite of activists/those who have chosen to leave school and self-educate through direct action). There are also designers, theatre artists, writers, filmmakers, cultural workers, among others. This might be oversimplifying it but I would say the most shared motivation is to be able to do and encourage the making/encountering of art beyond just churning out objects for the market/ gallery/auction system.

S: Are there any definitive distinction between those who are working in the visual arts, and other types of art, i.e., theatre, music, etc.?

E: If you are asking about whether there are discernibly distinct communities whose logics are tied to these media- or form-specific categories, I would say there are perceivable distinctions, but more and more, there has been a patent inclination for artists to cross over. This certainly isn't new if we think in terms of the by now arguably dated terms like community art, total theatre or even integrated arts, the latter being very much the battle cry of progressive artists who were working out of the cultural sector against the Marcos dictatorship. Again, in regard to collaboration and participation, those coming out of more traditional visual art training have had to ease into a non-singular author mode of making work. Logically, this is a less painful 'shift' for those coming from practices anchored on more collaborative forms like theatre and dance, which is not to say these latter forms are not essentially hierarchical because there are still power questions between let's say directors and performers, choreographers and dancers, etc.

S: Are there any particular art groups, or alternative spaces that do community engagement? 
E: Perhaps this would be a good time as any to think through how some artists display or project this perceived affinity with community engagement. My sense of it is that while there have been and still are groups/spaces that earnestly anchor their practice on community engagement, not a few would also latch on to the 'community/participation' label as a means to emplace themselves in the spectrum without being reflexive about whether this is just posturing. I'm certain this isn't the case only in the Philippines.

I'd also like to refer you to some material on a conference we did in 2002, called Locus: Interventions in Art Practice. Particular sessions there were specifically about this stream of work and would probably help put more context behind what seems to be now a more privileged or valorised kind of negotiating between art and sociality.

S: Can you tell me more about the motivation of these groups (to produce community works)?

E: Again I would refer you back to Locus, but to provide just a quick answer here, by the late 1960s-1970s there were artists aligning themselves with such organizations as the Community Arts Foundation and Kalinangan ng Lahi, which to my mind are two streams of initiatives seeking to close the art and life divide that was fuelling the debates between art for art's sake and what was variably called political/socially conscious art. These two aforementioned loose configurations had a particular interest in folk art and/or art in everyday life so the interventions took shape as workshops and exhibits of objects/activities seen as falling within those parameters. Yet since some of those involved were conversant with more modern impulses, they would also play and do improv on form and not see any problem with also engaging with more set off spaces (galleries/museums).

A later development in this regard was an initiative called CAYA (Center for the Advancement of Youth Artists), which, in the literature, appears to be more outrightly social realist. Young artists from the city would be sent out to the provinces to immerse themselves for extended periods with indigenous communities and the process of work then was meant to be governed by mutuality, the artists learning from craftspeople and vice versa. If we were to fast forward to today, the more likely to be considered as following on from this, but not necessarily adopting a lineage to such earlier undertakings would be groups like 98B (which has established itself in an old but now derelict trading district in Manila) and Project Space Pilipinas (which is in Quezon Province where artists who grew up on a surfeit of harvest-related festivals are trying to weave the tropes of the local into contemporary practice and vice versa).

Personally I would say much of the work is still in an exploratory/emergent phase with the artists still trying to find ways to navigate with contending interests and continuously evolving modes of work. There are also individual artist initiatives such as Martha Atienza's work with the Bantayan Island community (Cebu province) of seafarer families, and in our case, there would be Back to Square 1, initiated by Claro Ramirez (in 2014-2015 was working with urban informal settlers within the University of the Philippines). There are also more sporadically placed initiatives launched by autonomous groups (like Food not Bombs), which are not solely made up of artists thus launching interventions such as communal cooking, establishing info shops that sometimes become take off points for launching anywhere from urban community gardens to direct protest actions. 
S: Does this mean that Community Arts Foundation, Kalinangan ng Lahi and CAYA fall into the stream of artists working with communities or artist producing community-engaged works? The CAYA model as you explain seems to be different than the other two approaches?

E: I would say they fall within that same logic of wanting to bring art much nearer to a public that doesn't necessarily frequent galleries/museums/art centres. There is a difference in that CAYA had an outrightly immersive aspect, yes. If we are to take this forward to what is happening at the moment, much of the activity that is prominent at least in mainstream media is more in the vein of creative economy, which is more avowedly about building markets for what is made in communities than about rethinking modes of production and circulation.

S: As contemporary tropes, what kind of project have 98B and Project Space Pilipinas produced that differs from other groups? Would the setting of the project as part of an exhibition or art event thus qualify it to be seen as a contemporary approach in producing an audience/community oriented/engaged form of art?

E: The earlier groups, CAYA et al., would work across the forms of engagement tactics - immersion, workshops, improv events, exhibitions. Rather than consciously 'produce a community', my understanding of their work was that they would go to where the communities themselves were already organically converging. Kalinangan ng Lahi for instance, despite its fairly short existence, was avowedly about providing a centre for art so to speak that would serve as counterfoil to the then gentrifying cosmopolis that was Makati. It was sited in Cubao which is in Quezon City, a place which at least under President Manuel Quezon's time was meant as a working class neighbourhood as opposed to what Makati became, a business hub. I suppose what you are surfacing is the aspect of site-specificity, which is important too

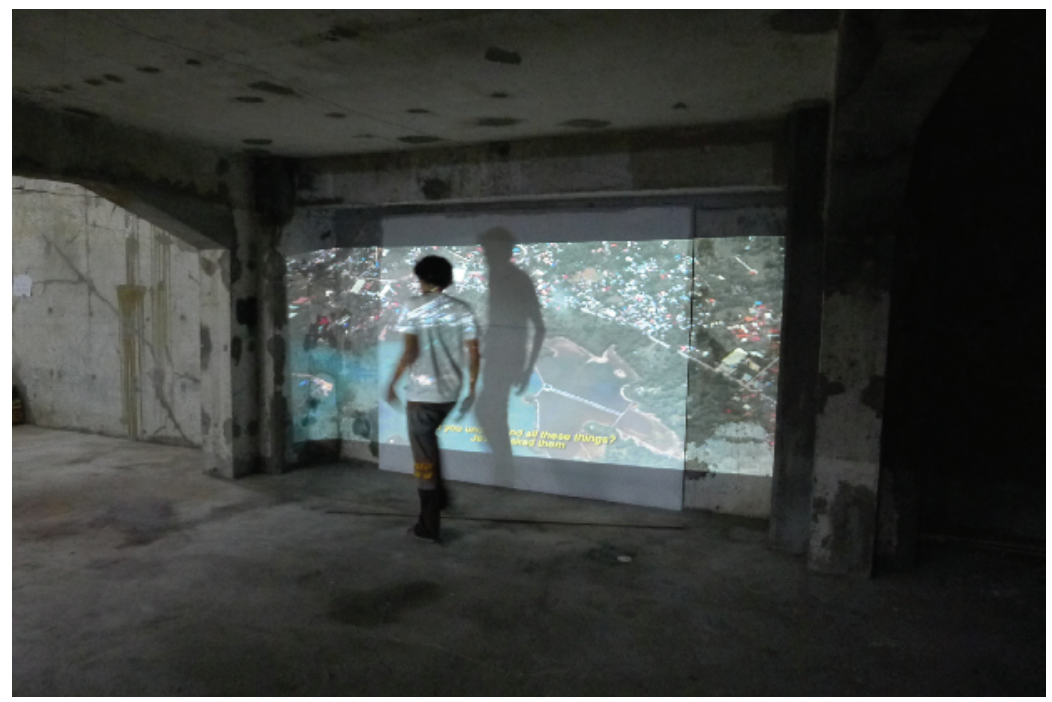

Figure 1: ESC Projects at Escolta where artists' projects are interspersed spatially. Photo courtesy of $98 B^{\prime}$ 's online photo archive. 


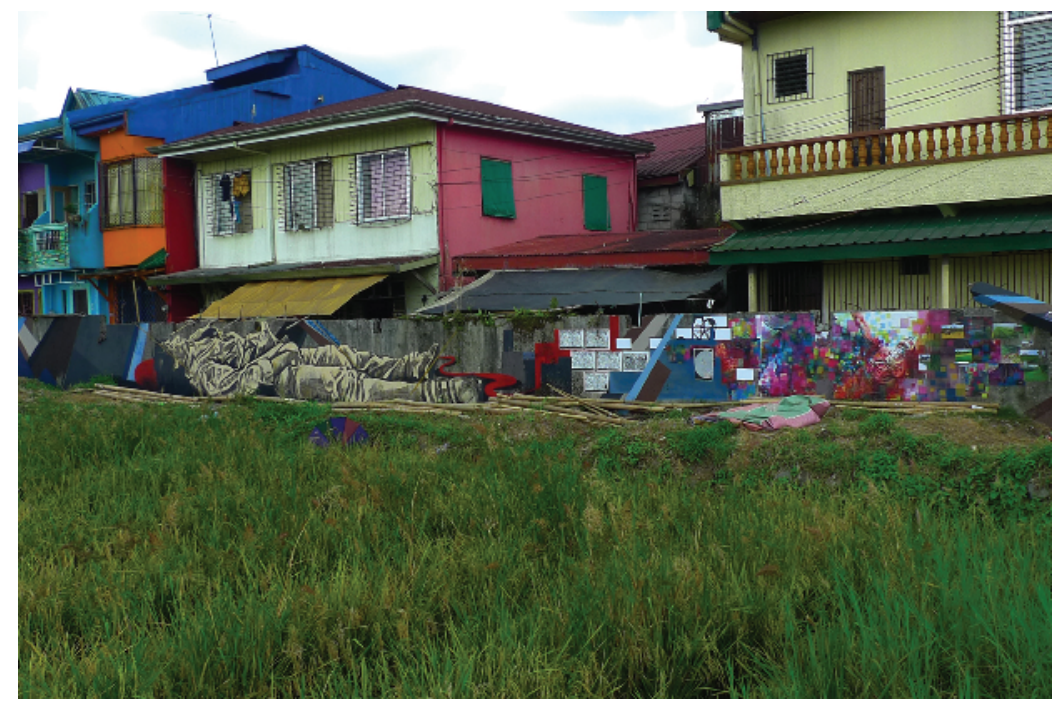

Figure 2: Murals by Windang Aesthetics Labor Army (W.A.L.A.) at Project Space Pilipinas' First Lucban Assembly/Systems of Irrigation in Lucban, Quezon. Photo courtesy of PSP's Facebook archive.

in the case of 98B and PSP. 98B set up in an underused building surrounded by other'dying' businesses in Escolta, which up through the American period was the 'go to' place for the rich and moneyed. 98B's work there activated a space for young designers and artists who, among other things, set up performances, exhibitions, block party-type events that have spurred occupants in the old trading/mercantile strip. I cannot as yet see though how those who actually were living and working there before 98B came upon it are being engaged as yet. PSP is another site-bound case in that the artists primarily making it up are from the agro-industrial province of Quezon and are thus, in principle, much more plugged into the everyday life so to speak of the once agricultural but now slowly urbanizing site. The investments in both space and mode of practice are different, and what you might say, tailored to the spatial circumstances.

S: In terms of the sustainability of such programmes, for example in Off Site/Out of Sight, how do you see such programmes being approached or organized elsewhere? Based on your experience, can such programmes be replicated in other parts of the Philippines? And does such programming result in the outcome that your team envisioned? Either short term or long term - after the programme ended?

E: Like I recall having written elsewhere, the learning curve in this project (Off Site/Out of Sight) was really steep. Aside from perhaps being too ambitious (we were also hoping to persuade artists who weren't initially inclined to work with communities to explore this mode for the first time). We knew from the get go that we needed help in terms of community organizing and we had been really reliant on the prior work done in the area. But there was a change in the internal university-governing structure that caught us flat footed. Despite the real inroads that were accomplished (including some 100 neighbourhood children and teens coming in on weekends and lesser 


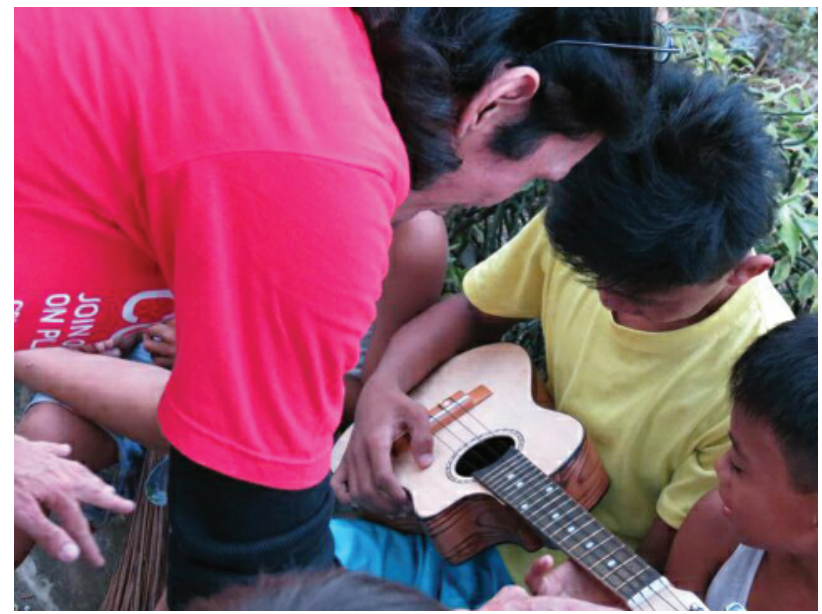

Figure 3: Impromptu ukulele lessons at Off Site, Out of Sight. Photo courtesy of Claro Ramirez.

numbers on weekdays) we were unable to really recover from losing access to the community organizers who had a much longer relationship built up with the community at large. I think we all learned so much from undertaking it. Personally I feel the degree of insight gained here absolutely exceeded what any graduate school would've enabled for me. For one thing, I think we should distinguish between sustainability and replicability. The only way I think the work could've continued was if we were able to get to the point that a much deeper ownership and more felt level of empowerment could've been made operational. But the university had other plans and shut us down and now a significant number of families that used to live in the community have been resettled, with houses demolished. So to cut this short, I think it is vital to remember that working with communities really means being context-specific

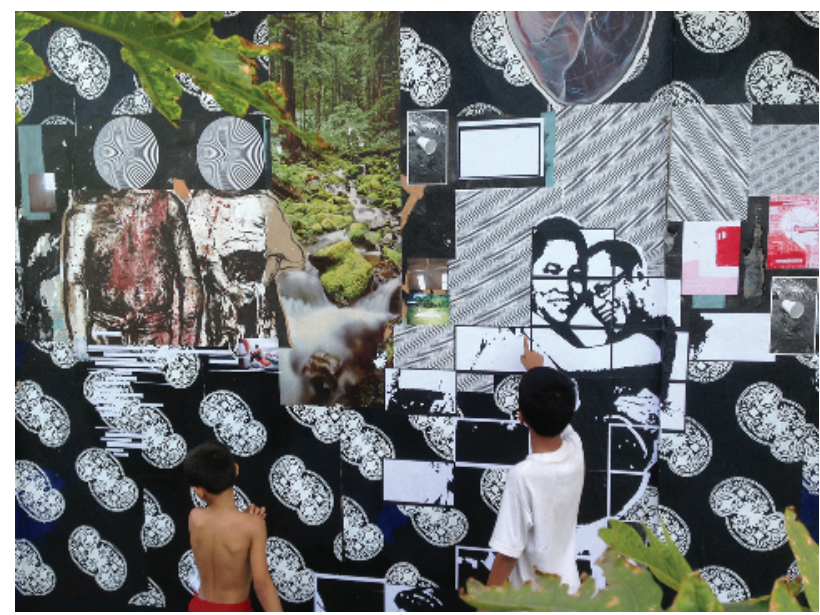

Figure 4: Children from C.P. Garcia at W.A.L.A. wall paste-up. Image courtesy of Eileen Legaspi. Photo by Mars Bugaoan. 
and responsive; there is no formula that can be taken from one project and simply applied to the next. Envisioning an 'end' or outcome needs to happen on the ground and with other stakeholders, not just artists/cultural workers who may be well-intentioned but still do not constitute the only core of desire in any such undertaking. Back to Square 1 does have its foundational principles (like coming back to a less compromised impulse to do art, activating space and modelling a more sustainable attitude toward resources, honouring the individual artist's agency while keeping to a sense of the communal, etc.) but the shape of a project, the pace, the social dynamic among costakeholders, among other things, all need to be less linear/deterministic.

S: In the international gathering of artists, curators and cultural workers, Locus, that you mentioned earlier (as its discussion and deliberation for both conferences Locus 1 and Locus 2 happened in 2002 - about fifteen to sixteen years ago) do you observe any significant changes in the realm of artistic practices that engaged with the public or the communities today? If yes, in what sense? If not, why?

E: I'd say the climate for doing this kind of work has gotten more play in mainstream discourse, including media. Since that has also led to more access to resources to take up this stream of practice, I think the need to keep on our toes (become even more reflexive and self-critical) of our own work becomes much more crucial.

\section{S: Thank you so much Eileen for insights of what is happening in the Philippines!}

E: You're most welcome; I'd just like to say there's a lot more to share and the story would be much enlivened by having other voices join the conversation.

\section{CONTRIBUTOR DETAILS}

Eileen Legaspi-Ramirez is an assistant professor of the Department of Art Studies of the University of the Philippines. Her current research focus encompasses attempts at variable forms of grassroots historiography, the reimagining and activation of contested space, and alternate modalities of exchange among artists navigating the institutional and extra-institutional. Her most recent essays include 'Southeast Asia in a crawl space: Tempering curatorial hubris', in Southeast Asia Spaces of the Curatorial (NTU Centre for Contemporary Art Singapore/Sternberg Press, 2017) and 'Shelved lives: The nineteen-seventies in the Purita Kalaw-Ledesma Trove', in The Life and Times of Purita Kalaw Ledesma (KLFI, 2017).

Sarena Abdullah and Eileen Legaspi-Ramirez have asserted their right under the Copyright, Designs and Patents Act, 1988, to be identified as the authors of this work in the format that was submitted to Intellect Ltd. 


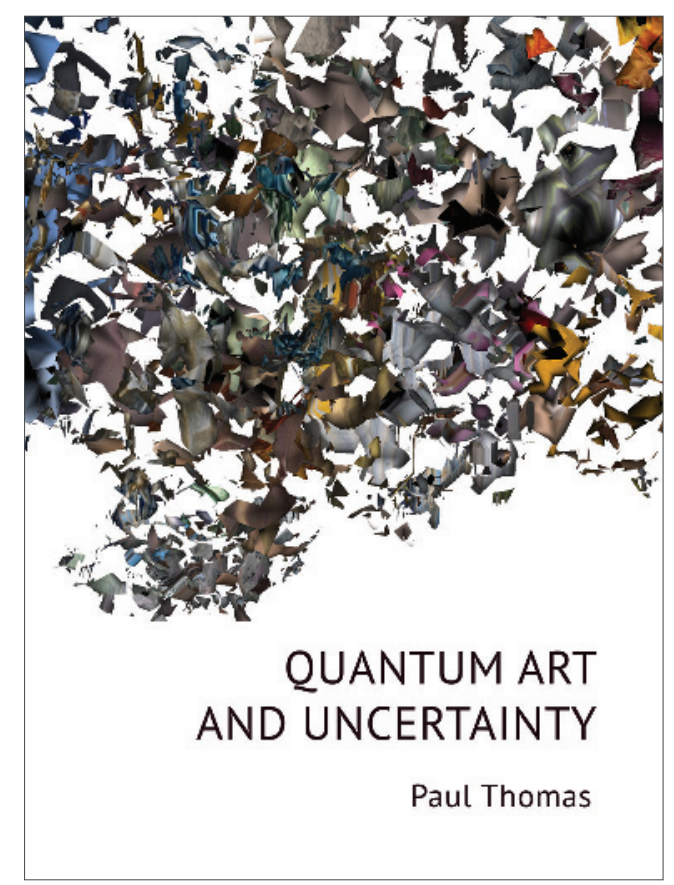

\section{Quantum Art and Uncertainty}

\section{By Paul Thomas}

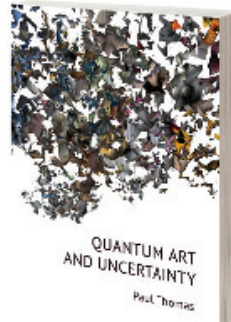

ISBN 978-1-78320-901-9 188 pp | £36, \$48

Paperback | Fall 2018

$230 \times 170 \mathrm{~mm}$

eBook available
At the core of both art and science, we find the twin forces of probability and uncertainty. However, these two worlds have been tenuously entangled for decades. On the one hand, artists continue to ask complex questions that align with a scientific fascination with new discoveries, and on the other hand, it is increasingly apparent that creativity and subjectivity inform science's objective processes and knowledge systems.

In order to draw parallels between art, science and culture, this publication explores the ways that selected artworks have contributed to a form of cultural pedagogy. It follows the integration of culture and science in artists' expressions to create meaningful experiences that expose the probabilities and uncertainties equally present in the world of science. 